\title{
BIỂU HIỆN LÂM SÀNG, HÌNH ẢNH NỘI SOI, ĐĂC ĐIỂM TRÊN KĨ THUÂT Đo ÁP LỰC VÀ NHU ĐỘNG THỰC QUẢN ĐỘ PHÂN GIẢl CAO Ở BẸNH NHÂN CO THÁT ĐOẠN XA THỰC QUẢN
}

\author{
Đào Việt Hằng ${ }^{1,2,3, \bowtie}$ và Lưu Thị Minh Huế ${ }^{1}$ \\ ${ }^{1}$ Viện Nghiên cứu và Đào tạo Tiêu hóa, Gan mật \\ ${ }^{2}$ Trường Đại học Y Hà Nội \\ 33ệnh viện Đại học Y Hà Nội
}

Nghiên cứu hồi cứu được tiến hành nhằm mô tả đặc điểm lâm sàng, hình ảnh nội soi và áp lực, nhu động thực quản trên bệnh nhân được chẩn đoán co thắt đoạn xa thực quản bằng đo áp lực và nhu động thực quản độ phân giải cao. Kết quả có 75 trong 7519 bệnh nhân được chẩn đoán co thắt đoạn xa thực quản trên đo áp lực và nhu động thực quản độ phân giải cao từ 3/2018 đến 8/2020 tại Viện Nghiên cứu và Đào tạo Tiêu hóa, Gan mật. Nhóm nghiên cứu gồm 62,7\% nữ, tuổi trung bình là 47,8 năm. Triệu chứng nuốt nghẹn và đau ngực gặp ở lần lượt 41,3\% và 30,7\%. Các triệu chứng phổ biến khác bao gồm cảm giác trào ngược (72,0\%), ợ hơi (56,0\%), nóng rát sau xương ức (49,3\%). 46,8\% bệnh nhân có tổn thương viêm thực quản trên nội soi. Trên đo áp lực và nhu động thực quản độ phân giải cao, trung vị tỉ lệ nhịp nuốt đến sớm là $30 \%$. Nhóm bệnh nhân có nuốt nghẹn và/hoặc đau ngực có áp lực tích hợp khi nghỉ của cơ thắt thực quản dưới trong vòng 4 giây (IRP4s) cao hơn so với nhóm không có hai triệu chứng trên. Tỉ lệ nhịp nuốt đến sớm không có mối liên quan tới biểu hiện nuốt nghẹn, đau ngực trên lâm sàng.

Từ khóa: co thắt đoạn xa thực quản, đo áp lực và nhu động thực quản.

\section{I. ĐẠT VẤN ĐÈ}

Co thắt đoạn xa thực quản (Distal esophageal spasm-DES) là một rối loạn nhu động thực quản hiếm gặp do hoạt động co bóp tự phát của cơ trơn thực quản. Rối loạn lần đầu tiên được mô tả lâm sàng vào năm 1889 trên 6 bệnh nhân có các triệu chứng nuốt khó kèm đau ngực. ${ }^{1}$ Nguyên nhân dẫn đến DES hiện còn chưa rõ ràng, tuy nhiên có mối liên quan với một số tình trạng như trào ngược dạ dày thực quản, một số rối loạn tâm thần hoặc sử dụng một số loại thuốc như thuốc phiện. Về cơ chế bệnh sinh, co thắt tự phát ở thực quản xuất hiện do sự bất thường của hệ thần kinh ức chế ở đám rối thần kinh

Tác giả liên hệ: Đào Việt Hằng

Trường Đại học Y Hà Nội

Email: hangdao.fsh@gmail.com

Ngày nhận: 06/02/2021

Ngày được chấp nhận: 08/03/2021 ruột. Bình thường, sóng nhu động thực quản hình thành từ hoạt động co bóp tuần tự của cơ trơn thực quản do tồn tại một chênh lệch về lực co bóp tăng dần dọc theo lòng thực quản từ đoạn gần về phía đoạn xa. Sự mất cân bằng do tác động của một số yếu tố thần kinh có thể dẫn đến tình trạng co bóp tự phát ở đoạn xa thực quản, đặc trưng bởi sự giảm độ trễ của co bóp (contractile latency)..$^{2,3}$ Về dịch tễ, tỉ lệ DES chiếm khoảng 4 - 10\% trong các bệnh nhân được tiến hành đo nhu động thực quản, ${ }^{4-6}$ và ở khoảng $13 \%$ trẻ có triệu chứng nuốt nghẹn kèm hoặc không kèm đau ngực. ${ }^{7}$ Biểu hiện lâm sàng của DES đa dạng, với hai triệu chứng thường gặp nhất là nuốt khó và đau ngực, tuy nhiên chúng lại không đặc hiệu, và cũng thường gặp ở các rối loạn khác của thực quản. DES có đặc trưng bởi hình ảnh xoắn ốc ở đoạn xa thực quản trên 
hình ảnh chụp Xquang baryt thực quản, có thể quan sát thấy tình trạng co bóp mạnh, không đồng bộ, có thể kết hợp với tổn thương niêm mạc do ứ đọng dịch trong quá trình nội soi. ${ }^{2}$ Hiện nay đo áp lực và nhu động thực quản độ phân giải cao (HRM) được coi là tiêu chuẩn vàng trong chẩn đoán DES do có thể đánh giá được đồng thời hình thái nhu động của thực quản, áp lực các thành phần cơ thắt thực quản và áp lực cơ thắt thực quản dưới. Điều này giúp phân biệt $D E S$ với các tình trạng rối loạn nhu động thực quản khác có biểu hiện lâm sàng tương tự như co thắt tâm vị, thực quản Jackhammer, tắc nghẽn đường ra thực quản.

Hiện nay, tại Việt Nam phương pháp HRM còn tương đối mới, chưa có nghiên cứu nào đánh giá các bệnh nhân có tình trạng DES. Do đó, nhóm nghiên cứu tiến hành nghiên cứu nhằm mục tiêu: Mô tả đặc điểm lâm sàng, kết quả nội soi, và kết quả HRM trên các đối tượng co thắt đoạn xa thực quản (DES).

\section{II. ĐÓI TƯỢNG VÀ PHƯƠNG PHÁP}

\section{1. Đối tượng}

Nghiên cứu mô tả trên các đối tượng được chẩn đoán co thắt đoạn xa thực quản (DES) trên đo áp lực và nhu động thực quản độ phân giải cao (HRM) từ 3/2018 đến 8/2020 tại phòng khám đa khoa Hoàng Long - Viện Nghiên cứu và Đào tạo Tiêu hóa, Gan mật.

Các thông tin thu thập bao gồm nhân khẩu học, triệu chứng lâm sàng, điểm FSSG bao gồm điểm FSSG tổng và các điểm FSSG thành phần (điểm FSSG trào ngược và điểm FSSG nhu động), điểm GERDQ, kết quả nội soi, và kết quả đo HRM.

\section{Phương pháp}

Kĩ thuật đo áp lực và nhu động thực quản (HRM)

Kĩ thuật đo HRM được tiến hành trên hệ thống máy Solar GI (nhà sản xuất Laborie, Hà Lan), sử dụng catheter bơm nước 22 kênh, phần mềm phân tích kết quả MMS. Độ mạnh của co bóp $(\mathrm{DCl})$ được tính bằng tích số của cường độ, thời gian co bóp và độ dài (tính từ đoạn gần đến đoạn xa thực quản) của co bóp (đơn vị mmHg.cm.giây). Độ trễ của co bóp (DL) được tính từ điểm cơ thắt thực quản trên bắt đầu giãn cho đến điểm mà tại đó vận tốc dẫn truyền của sóng co bóp thực quản thay đổi đột ngột. Nhịp nuốt đến sớm được xác định khi có giá trị $\mathrm{DCl} \geq 450 \mathrm{mmHg} . \mathrm{cm}$.s và $\mathrm{DL}<4.5$ giây.

Kết quả đo HRM được phân tích theo phân loại Chicago v3.0 bởi bác sĩ đã được đào tạo về kĩ thuật HRM. DES được chẩn đoán khi IRP4s (áp lực tích hợp khi nghỉ trong 4 giây của cơ thắt thực quản dưới) bình thường và $\geq 20 \%$ nhịp nuốt đến sớm. Các bản đo có kết quả là DES được đọc lại độc lập bởi một bác sĩ khác.

\section{Xử lý số liệu}

Số liệu được nhập vào phần mềm EpiData và xử lí bằng phần mềm SPSS version 22.0. Các biến định tính được biểu diễn dưới dạng tî̉ lệ (phần trăm), các biến định lượng được biểu diễn dưới dạng trung bình \pm độ lệch chuẩn. Sự khác biệt giữa các nhóm độc lập kiểm định bằng Chi-square test, Independentsample T-test. Mối tương quan giữa triệu chứng và tỉ lệ nhịp nuốt đến sớm được khảo sát bằng hồi quy nhị phân đơn biến.

\section{4. Đạo đức nghiên cứu}

Nghiên cứu đã được thông qua Hội đồng đạo đức Viện Nghiên cứu $Y$ học Đinh Tiên Hoàng mã IRB-1909 ngày 01 tháng 03 năm 2020. 


\section{KẾT QUẢ}

Từ tháng 3/2018 đến 8/2020, 7519 bệnh nhân được tiến hành đo HRM, trong đó 75 đối tượng (1\%) thoả mãn tiêu chuẩn lựa chọn DES. Nữ chiếm $62,7 \%$, tuổi trung bình là 47,8 $\pm 13,6$ (tuổi). Tiền sử bệnh lí xơ cứng bì hệ thống và đái tháo đường lần lượt gặp ở lần lượt 1,3\% và 2,7\%, không ghi nhận tiền sử về rối loạn tâm-thần kinh. Giá trị BMI trung bình của nhóm nghiên cứu là 22,1 $\pm 3,0(\mathrm{~kg} /$ $\left.\mathrm{m}^{2}\right)$, tỉ lệ thừa cân/béo phì chiếm 17,6\% $\left(\mathrm{BMI} \geq 25 \mathrm{~kg} / \mathrm{m}^{2}\right)$, thiếu cân chiếm 10,7\% $\left(\mathrm{BMl}<18,5 \mathrm{~kg} / \mathrm{m}^{2}\right)$.

Bảng 1 trình bày về đặc điểm chung của nhóm nghiên cứu. Các triệu chứng thường gặp là cảm giác trào ngược, ợ hơi, nóng rát sau xương ức, và đau thượng vị. Các triệu chứng nuốt nghẹn và đau ngực gặp lần lượt là $41,3 \%$ và $30,7 \%$. Tỉ lệ bệnh nhân có nuốt nghẹn và/hoặc đau ngực là $56 \%$. Điểm FSSG và GERDQ trung bình lần lượt là 12,5 và 6,3 , trong đó $73,3 \%$ và $30,7 \%$ có điểm FSSG $\geq 8$ và $G E R D Q \geq 8$. Thời gian biểu hiện triệu chứng có trung vị bằng 10 tháng, khoảng tứ phân vị 3-24 (tháng).

Trên nội soi dạ dày-thực quản, tỉ lệ viêm thực quản trào ngược là 46,8\%, trong đó tất cả bệnh nhân đều có tổn thương viêm thực quản độ $A$ theo phân loại Los Angeles. Tổn thương Barrett thực quản, và thoát vị hoành chỉ gặp ở 1 bệnh nhân. Có 1 bệnh nhân được ghi nhận theo dõi tình trạng rối loạn co bóp thực quản, và 3 bệnh nhân có kết quả theo dõi co thắt tâm vị trên nội soi.

Bảng 1. Đặc điểm của đối tượng nghiên cứu

Triệu chứng lâm sàng, $\mathrm{n}$ (\%)

\begin{tabular}{cc}
\hline Nóng rát sau xương ức & $37(49,3)$ \\
\hline Cảm giác trào ngược & $54(72,0)$ \\
\hline Ợ hơi & $42(56,0)$ \\
\hline Ợ chua & $34(45,3)$ \\
\hline Đau thượng vị & $37(49,3)$ \\
\hline Nôn & $4(5,3)$ \\
\hline Buồn nôn & $24(32,0)$ \\
\hline Đầy bụng & $38(50,7)$ \\
\hline Đau ngực & $23(30,7)$ \\
\hline Nuốt nghẹn & $31(41,3)$ \\
\hline Gầy sút cân & $12(16,0)$ \\
\hline Ho kéo dài & $9(12,0)$ \\
\hline Viêm họng tái phát & $29(38,7)$ \\
\hline Khó thở & $7(9,3)$ \\
\hline
\end{tabular}


Điểm lâm sàng, trung bình \pm độ lệch chuẩn hoặc n(\%)

\begin{tabular}{cc}
\hline Cảm giác có khối ở cổ & $30(40,0)$ \\
\hline FSSG tổng & $12,5 \pm 7,6$ \\
\hline FSSG trào ngược & $7,6 \pm 5,2$ \\
\hline FSSG nhu động & $5,0 \pm 3,5$ \\
\hline FSSG $\geq 8$ & $55(73,3)$ \\
\hline GERDQ & $6,3 \pm 3,0$ \\
\hline GERDQ $\geq 8$ & $23(30,7)$ \\
\hline
\end{tabular}

Bảng 2 mô tả đặc điểm trên đo HRM của nhóm nghiên cứu. Bệnh nhân có biểu hiện nuốt nghẹn và/hoặc đau ngực có IRP4s cao hơn so với nhóm không có hai triệu chứng trên. Các giá trị khác trên đo HRM không có sự khác biệt có ý nghĩa thống kê giữa hai nhóm.

Bảng 2. Đặc điểm trên đo áp lực và nhu động thực quản (HRM)

\begin{tabular}{lcccc}
\hline \multicolumn{1}{c}{ Đặc điểm } & $\begin{array}{c}\text { Chung } \\
(\mathbf{n = 7 5 )}\end{array}$ & $\begin{array}{c}\text { Nhóm } \mathbf{A}^{*} \\
\mathbf{( n = 4 2 )}\end{array}$ & $\begin{array}{c}\text { Nhóm } \mathbf{B}^{* *} \\
\mathbf{( n = 3 3 )}\end{array}$ & $\mathbf{p}$ \\
\hline Áp lực cơ thắt thực quản trên (UES) & $53,9 \pm 23,6$ & $53,5 \pm 22,0$ & $54,6 \pm 25,9$ & 0,84 \\
\hline Áp lực cơ thắt thực quản dưới (LES) & $22,0 \pm 10,5$ & $9,5 \pm 1,5$ & $11,8 \pm 2,1$ & 0,78 \\
\hline Áp lực LES < 10mmHg & $9(12)$ & $4(9,5)$ & $5(15,2)$ & $\left(^{* * *}\right)$ \\
\hline Áp lực LES > 45 mmHg & $1(1,3)$ & 0 & $1(3,0)$ & $\left(^{* * *}\right)$ \\
\hline IRP4s & $8,0 \pm 4,0$ & $4,0 \pm 0,6$ & $3,8 \pm 0,7$ & 0,042 \\
\hline IRP4s < 5mmHg & $21(28)$ & $10(23,8)$ & $11(33,3)$ & 0,36 \\
\hline DCl trung bình 10 nhịp nuốt đơn & $1023,3 \pm 507,8$ & $571,6 \pm 88,2$ & $416,3 \pm 72,5$ & 0,47 \\
\hline DL trung bình 10 nhịp nuốt & $4,5 \pm 1,0$ & $4,6 \pm 1,0$ & $4,4 \pm 1,0$ & 0,53 \\
\hline
\end{tabular}

*Nhóm $A$, nhóm có triệu chứng nuốt nghẹn và/hoặc đau ngực, ${ }^{* *}$ Nhóm $B$, không có triệu chứng nuốt nghẹn và đau ngực, $\left({ }^{* * *}\right)$ không kiểm định do cỡ mẫu các nhóm nhỏ.

Trung vị tỉ lệ nhịp nuốt đến sớm trong nhóm nghiên cứu chung là 30\%. Hình 1 mô tả đặc điểm nhịp nuốt đến sớm trong cả nhóm nghiên cứu, trong nhóm có triệu chứng nuốt nghẹn và/hoặc đau ngực, và nhóm không có triệu chứng nuốt nghẹn và đau ngực. Trong đó, 45,3\% bệnh nhân có $20 \%$ nhịp nuốt đến sớm, 30,7\% bệnh nhân có 30\% nhịp nuốt đến sớm. Tỉ lệ bệnh nhân có số nhịp nuốt đến sớm > 50\% là $5,3 \%$. Không có sự khác biệt có ý nghĩa thống kê về tỉ lệ nhịp nuốt đến sớm > 50\% giữa hai nhóm $A$ và $B$. 


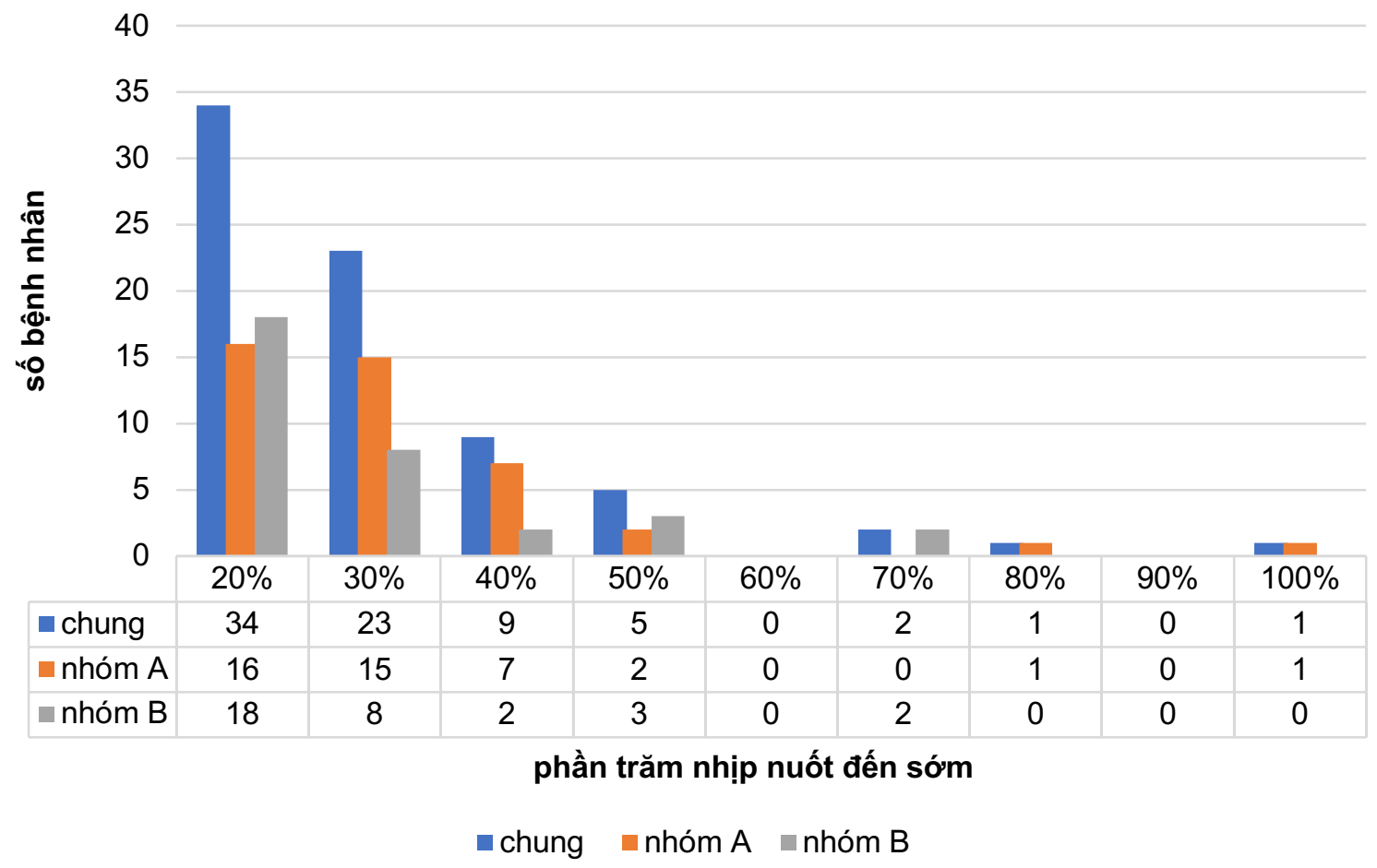

Hình 1. Phần trăm nhịp nuốt đến sớm ở bệnh nhân DES

Phân tích hồi quy đơn biến giữa tỉ lệ nhịp nuốt đến sớm với biểu hiện triệu chứng nuốt nghẹn hoặc đau ngực cho thấy không có mối tương quan giữa triệu chứng nuốt nghẹn với tỉ lệ nhịp nuốt đến sớm $(\mathrm{OR}=1,01,95 \% \mathrm{Cl}: 0,98-1,04)$, cũng như giữa triệu chứng đau ngực với tỉ lệ nhịp nuốt đến sớm $(\mathrm{OR}=1,00,95 \% \mathrm{Cl}: 0,96-1,03)$.

\section{BÀN LUẬN}

Trong nghiên cứu này, chúng tôi mô tả đặc điểm lâm sàng, kết quả nội soi và kết quả đo HRM trên 75 bệnh nhân có chẩn đoán co thắt đoạn xa thực quản (DES) trên đo áp lực và nhu động thực quản độ phân giải cao (HRM). Tỉ lệ DES trong thời gian nghiên cứu thấp hơn nghiên cứu của $\mathrm{K}$ Tsuboi $(4,9 \%)$ và $\mathrm{C}$ Almansa (4 - 7\%), tuy nhiên khá tương đồng với tỉ lệ trên 3400 bệnh nhân đo HRM tại Washington $(0,9 \%)^{5,8,9}$ Tuổi trung bình của nhóm nghiên cứu là 47,8 năm, tương đồng với nghiên cứu trước có kết quả tuổi trung bình chẩn đoán DES là 50 tuổi. ${ }^{10,11}$

So với các nghiên cứu trước đây tại Mĩ và Nhật, tỉ lệ triệu chứng nuốt nghẹn của chúng tôi thấp hơn, tỉ lệ triệu chứng đau ngực thì khá tương đồng. ${ }^{4,5}$ Tỉ lệ triệu chứng nuốt nghẹn và đau ngực trong nghiên cứu này cao hơn so với nhóm bệnh nhân trào ngược dạ dày-thực quản, tuy nhiên thấp hơn ở nhóm bệnh nhân co thắt tâm vị (tỉ lệ nuốt nghẹn và đau ngực gặp ở $28,1 \%$ và $24,2 \%$ bệnh nhân có triệu chứng trào ngược dạ dày thực quản, và lần lượt là 92,9\% và 42,9\% ở bệnh nhân co thắt tâm vị). ${ }^{12,13}$ Thời gian có biểu hiện triệu chứng tương đối ngắn hơn so với nghiên cứu của tác giả $C$ Almansa trên 108 bệnh nhân DES trên đo HRM (48 tháng). ${ }^{4}$ Cũng trong nghiên cứu này, nhóm tác giả ghi nhận thời gian từ lần đầu bệnh nhân tìm kiếm đến cơ sở y tế đến thời điểm lần đầu được 
chẩn đoán DES trung bình khoảng 8 tháng. Sự chậm trễ trong chẩn đoán này được cho là do các triệu chứng lâm sàng không đặc hiệu, các chuyên gia về nhu động đường tiêu hóa còn thiếu, cũng như việc áp dụng các kĩ thuật thăm dò chưa chính xác. ${ }^{4}$ Đặc biệt, trong bối cảnh tại Việt Nam, kĩ thuật HRM còn là tương đối mới, chưa được áp dụng vào thực tiễn lâm sàng, do đó việc tiếp cận chẩn đoán DES hiện còn nhiều hạn chế.

Trên nội soi ghi nhận một trường hợp có rối loạn nhu động thực quản. Điều đó cho thấy, tỉ lệ phát hiện các rối loạn co bóp tại thực quản trên nội soi là khá thấp, dẫn đến việc chậm trễ trong chẩn đoán được DES nếu chỉ dựa vào kết quả nội soi. Kết quả nội soi còn ghi nhận 3 trường hợp theo dõi co thắt tâm vị. Một số trường hợp DES có tình trạng ứ đọng dịch, và bất thường co bóp ở đoạn xa thực quản tương đối giống với hình ảnh nội soi của các bệnh nhân co thắt tâm vị. Ngoài việc hình ảnh nội soi có thể không đặc hiệu cho các rối loạn nhu động thực quản như DES và co thắt tâm vị, thực tế vẫn có một tỉ lệ bệnh nhân có sự chuyển biến DES thành co thắt tâm vị trong thời gian theo dõi. Một nghiên cứu tiến cứu trên 32 bệnh nhân DES cho thấy 1 bệnh nhân tiến triển thành co thắt tâm vị sau 10,6 năm. ${ }^{14}$ Tương tự một nghiên cứu khác, 5 trên 35 bệnh nhân DES tiến triển thành co thắt tâm vị sau thời gian theo dõi trung bình là 2,1 (1 - 4) năm. ${ }^{15}$ Các nghiên cứu trên cho thấy tỉ lệ chuyển đổi từ DES sang co thắt tâm vị còn thấp, các yếu tố có thể dự đoán sự dịch chuyển còn chưa rõ ràng, tuy nhiên việc lặp lại đo HRM sau một thời gian điều trị DES là cần thiết cho bệnh nhân.

Tỉ lệ viêm thực quản trào ngược trên nội soi trong nghiên cứu của chúng tôi là 46,8\%. Sự liên quan giữa trào ngược dạ dày thực quản và DES hiện còn chưa rõ ràng. Các nghiên cứu trước đã chỉ ra rằng một số các rối loạn nhu động thực quản có thể gây nên tình trạng ứ đọng dịch từ đó gây nên tổn thương niêm mạc thực quản, ngược lại các tổn thương niêm mạc thực quản do trào ngược cũng có thể gây nên các rối loạn về nhu động. ${ }^{16-18}$ Do đó, biểu hiện lâm sàng của DES có thể gây nên do rối loạn nhu động, cũng có thể do tình trạng tiếp xúc với acid bất thường do trào ngược dạ dày-thực quản. Chính vì sự tác động này, điều trị trào ngược dạ dày thực quản nên được cân nhắc trên các bệnh nhân DES. ${ }^{2,19}$

Trên đo HRM, các bệnh nhân có triệu chứng nuốt nghẹn và/hoặc đau ngực có giá trị IRP4s cao hơn so với nhóm không có triệu chứng trên, tuy nhiên áp lực cơ thắt thực quản dưới và độ mạnh của co bóp thực quản không có sự khác biệt có ý nghĩa giữa hai nhóm. Một nghiên cứu trên 217 bệnh nhân DES tại Nhật Bản cho thấy áp lực cơ thắt thực quản dưới cao hơn ở nhóm bệnh nhân có triệu chứng nuốt nghẹn và/ hoặc đau ngực và có mối liên quan giữa triệu chứng nuốt nghẹn với tî lệ co bóp tự phát tại thực quản. Tuy nhiên, trong nghiên cứu của chúng tôi thì không có sự khác biệt có ý nghĩa thống kê về các giá trị trên đo HRM giữa hai nhóm có triệu chứng nuốt nghẹn và/hoặc đau ngực và nhóm không có hai triệu chứng trên, cũng không có mối liên quan giữa tỉ lệ nhịp nuốt đến sớm với biểu hiện triệu chứng nuốt nghẹn, đau ngực. Điều này có thể do cỡ mẫu trong nghiên cứu của chúng tôi còn ít vì đây là một rối loạn nhu động thực quản hiếm gặp hoặc do sự khác biệt về yếu tố chủng tộc giữa các nghiên cứu và sẽ cần thêm nhiều dữ liệu để phân tích mối liên quan này.

HRM là một trong những kĩ thuật thăm dò nhu động đường tiêu hóa còn tương đối mới tại Việt Nam, nghiên cứu của chúng tôi đã cung cấp những số liệu ban đầu, từ đó có thể giúp các nhà lâm sàng có cái nhìn tổng quan về $D E S$ - một rối loạn nhu động còn chưa được quan 
tâm tại Việt Nam. Trong tương lai, các nghiên cứu tiến cứu với bệnh nhân DES nên được tiến hành để theo dõi rối loạn nhu động thực quản qua thời gian; đánh giá, so sánh hiệu quả của các phương pháp điều trị DES khác nhau. Từ đó để việc tiếp cận chẩn đoán và điều trị DES trong tương lai được rõ ràng và thống nhất.

\section{KẾT LUẬN}

DES là một rối loạn nhu động thực quản hiếm gặp, biểu hiện triệu chứng không đặc hiệu và trong thời gian dài. Tuy nuốt nghẹn và đau ngực là hai triệu chứng thường gặp của DES nhưng không có mối liên quan giữa tỉ lệ nhịp nuốt đến sớm với biểu hiện lâm sàng. Tỉ lệ cao bệnh nhân DES có tổn thương viêm thực quản trào ngược trên nội soi. Các giá trị trên đo HRM không có sự khác biệt giữa nhóm có triệu chứng nuốt nghẹn và/hoặc đau ngực với nhóm không hai triệu chứng trên.

\section{LỜ'I CẢM ƠN}

Nghiên cứu nằm trong đề tài cấp nhà nước của Bộ Khoa học và Công nghệ "Nghiên cứu đánh giá rối loạn vận động và bài tiết một số bệnh lý dạ dày, thực quản" mã số ĐTĐLCN.04/20.

\section{TÀI LIẸU THAM KHẢO}

1. Osgood H. A peculiar form of oesorhagismus. The New England Journal of Medicine. 1889;120:401-405.

2. Gorti H, Samo S, Shahnavaz N, Qayed E. Distal esophageal spasm: Update on diagnosis and management in the era of highresolution manometry. World J Clin Cases. 2020;8(6):1026-1032.

3. Paterson WG. Esophageal peristalsis. GI Motility online. 2006.

4. Almansa C, Heckman MG, DeVault $\mathrm{KR}$, Bouras E, Achem SR. Esophageal spasm: demographic, clinical, radiographic, and manometric features in 108 patients. Dis Esophagus. 2012;25(3):214-221.

5. Tsuboi K, Mittal SK. Diffuse esophageal spasm: has the term lost its relevance? Analysis of 217 cases. Dis Esophagus. 2011;24(5):354359.

6. Katz PO, Dalton CB, Richter JE, Wu WC, Castell DO. Esophageal testing of patients with noncardiac chest pain or dysphagia. Results of three years' experience with 1161 patients. Ann Intern Med. 1987;106(4):593-597.

7. Rosen JM, Lavenbarg T, Cocjin J, Hyman PE. Diffuse esophageal spasm in children referred for manometry. J Pediatr Gastroenterol Nutr. 2013;56(4):436-438.

8. Almansa C, Achem SR. [Diffuse esophageal spasm (DES). Practical concepts of diagnosis and treatment]. Revista de gastroenterologia de Mexico. 2007;72(2):136145.

9. Crespin OM, Tatum RP, Yates RB, et al. Esophageal hypermotility: cause or effect? Dis Esophagus. 2016;29(5):497-502.

10. Clouse RE, Staiano A. Contraction abnormalities of the esophageal body in patients referred to manometry. A new approach to manometric classification. Digestive diseases and sciences. 1983;28(9):784-791.

11. Reidel WL, Clouse RE. Variations in clinical presentation of patients with esophageal contraction abnormalities. Digestive diseases and sciences. 1985;30(11):1065-1071.

12. Đào Việt Hằng, Trần Thị Thanh Lịch, Lưu Thị Minh Huế. Mối liên quan giữa điểm FSSG với nhu động thực quản và áp lực co thắt thực quản dưới ở bệnh nhân trào ngược dạ dày thực quản. Tạp chí nghiên cứru Y học. 2020;130(6):83-90.

13. Nguyễn Thùy Linh, Trần Thị Thu Trang, Lưu Thị Minh Huế, Đào Việt Hằng. 
Evaluation of clinical characteristics and lower esophageal sphincter pressure on high resolution manomoetry in achalasia patients after treatment. Tạp chí Khoa học và Công nghệ Việt Nam. 2020;accepted.

14. Khatami SS, Khandwala F, Shay SS, Vaezi MF. Does diffuse esophageal spasm progress to achalasia? A prospective cohort study. Digestive diseases and sciences. 2005;50(9):1605-1610.

15. Fontes LH, Herbella FA, Rodriguez TN, Trivino T, Farah JF. Progression of diffuse esophageal spasm to achalasia: incidence and predictive factors. Dis Esophagus. 2013;26(5):470-474.

16. Liu L, Li S, Zhu K, et al. Relationship between esophageal motility and severity of gastroesophageal reflux disease according to the Los Angeles classification. Medicine. 2019;98(19):e15543.

17. Chrysos E, Prokopakis G, Athanasakis $E$, et al. Factors affecting esophageal motility in gastroesophageal reflux disease. Archives of surgery (Chicago, III : 1960). 2003;138(3):241246.

18. Lin S, Li H, Fang X. Esophageal Motor Dysfunctions in Gastroesophageal Reflux Disease and Therapeutic Perspectives. Journal of neurogastroenterology and motility. 2019;25(4):499-507.

19. Achem SR, Gerson LB. Distal esophageal spasm: an update. Curr Gastroenterol Rep. 2013;15(9):325.

\section{Summary}

\section{CLINICAL SYMPTOMS, ENDOSCOPIC FINDINGS AND HIGH RESOLUTION MANOMETRYC RESULTS IN PATIENTS WITH DISTAL ESOPHAGEAL SPASM}

A retrospective study was conducted to describe clinical symptoms, endoscopic findings, and high-resolution manometry (HRM) results in patients with distal esophageal spasm (DES). There were 75 of 7519 patients diagnosed of DES on HRM between 3/2018 to 8/2020 at the Institute of Gastroenterology and Hepatology. The study sample included $62.7 \%$ women, the mean age was 47.8 years. The prevalence of dysphagia and chest pain were $41.3 \%$ and $30.7 \%$, respectively. Other common symptoms included regurgitation (72.0\%), belching (56.0\%), and heartburn $(49.3 \%) .46 .8 \%$ of patients had erosive esophagitis on endoscopy. On HRM, the median percentage of premature swallows was $30 \%$. Patients with dysphagia with or without chest pain had significantly higher 4-second integrated relaxation pressure (IRP4s) than those without these symptoms. There was no correlation between dysphagia or chest pain and the percentage of premature contraction.

Keyword: distal esophageal spasm, esophageal manometry. 